\title{
Genetics of esterase-mediated insecticide resistance in the aphid Schizaphis graminum
}

\author{
STANLEY DEAN RIDER, J R.†, GERALD E. WILDE* + \& SRINIVAS KAMBHAMPATI \\ $\dagger$ †epartment of Entomology, Purdue University, West Lafayette, IN 47907, U.S.A. and \$Department of Entomology, \\ Kansas State University, Manhattan, KS 66506, U.S.A.
}

\begin{abstract}
The genetics of organophosphate resistance, including the pattern of inheritance and the underlying genetic mechanism, were investigated in the aphid Schizaphis graminum (the greenbug). Resistant greenbugs with pattern 1 (R1) and pattern 2 (R2) esterase and susceptible (S) greenbugs were induced into the sexual cycle and crossed. Each resistance-associated esterase pattern in the greenbug was inherited in a Mendelian fashion as a single gene. An aphid clone that displayed both resistance-associated esterase patterns was produced in the $\mathrm{F}_{1}$ generation of a cross between R2 and R1 insects, and was designated pattern 3 (R3). DNA from different $\mathrm{R} 1$ aphids and the R3 aphid clone displayed a restriction fragment pattern different from that of R2 and S clones, and about a twofold increase in hybridization compared with $\mathrm{S}$ aphids. DNA from R2 clones showed no restriction fragment differences or increased hybridization signal compared to $\mathrm{S}$ insects. These findings suggest that the mechanism behind the R1 esterase activity may be gene amplification, but that the R2 elevated esterase activity may result from a different genetic mechanism.
\end{abstract}

Keywords: aphid, DNA methylation, esterase, gene amplification, greenbug, insecticide resistance, Schizaphis graminum.

\section{Introduction}

The greenbug Schizaphis graminum (Rondani) is an aphid pest of small grains. Control methods for greenbugs have included natural enemies, crop cultivars resistant to the pest, and chemical insecticides. The ability of greenbug populations to overcome host plant resistance has resulted in a continual need for the use of pesticides, which, in turn, has resulted in the development of insecticide-resistant strains of the greenbug.

In the greenbug, organophosphate resistance results from detoxification of the insecticide by esterases (primarily by sequestering, not hydrolysing the insecticide) and reduced acetylcholinesterase sensitivity (Siegfried \& Ono, 1993; Ono et al., 1994). When single aphid homogenates were electrophoresed in native polyacrylamide gels and the gels were stained for nonspecific esterase activity, individuals with one of two different elevated esterase phenotypes (pattern 1 and pattern 2) were discovered (Wilde et al., 1994; Shufran et al., 1996). These elevated esterase polymorphisms have been charac-

\footnotetext{
*Correspondence. E-mail: gwilde@oz.oznet.ksu.edu
}

terized and associated with different levels of resistance. Susceptible (S) insects showed no elevated esterase activity or resistance to insecticides (Shufran et al., 1996). Insects with the pattern 1 phenotype display a single slowly migrating elevated esterase which confers up to 50 -fold resistance to parathion (an organophosphate insecticide), whereas individuals of the pattern 2 phenotype display a series of three fast-moving esterases with elevated activity and up to 200 -fold resistance to parathion (Shufran et al., 1996; Rider et al., 1998). By convention, these electrophoretic patterns in the greenbug are referred to as R1 (pattern 1) and R2 (pattern 2) and should not be confused with resistance levels described in the literature dealing with the aphid Myzus persicae. No field-collected greenbug has been discovered in which both elevated esterase patterns were present (Shufran et al., 1996). Figure 1 provides representative esterase profiles for S, R1 and R2 insects as well as a novel esterase pattern found in an offspring derived from this study (see Results and discussion section).

In Culex spp. (mosquitoes) and Myzus spp. (aphids), gene amplification has been shown to underlie esterase-mediated insecticide resistance 
(Mouches et al., 1986; Field et al., 1988). In the case of Myzus persicae, arrays involving two different amplified esterase genes have been localized to different chromosomal locations (Blackman et al., 1996). Each of these arrays is inherited in a Mendelian fashion, although amplified regions associated with a translocation were not inherited at the expected frequency (Blackman et al., 1996). Similarly, amplified genes in Culex quinquefasciatus are inherited as a block, but copy number changes can occur through different molecular drive events (Ferrari \& Georghiou, 1991). In both Myzus persicae and Culex quinquefasciatus, new genotypes with markedly different amplification levels can arise when offspring inherit different arrays (Ferrari \& Georghiou, 1991; Blackman et al., 1996). It is also noteworthy that increased methylation of esterase gene sequences in Myzus persicae is associated with increased levels of gene expression and insecticide resistance (Field \& Devonshire, 1992). For green-

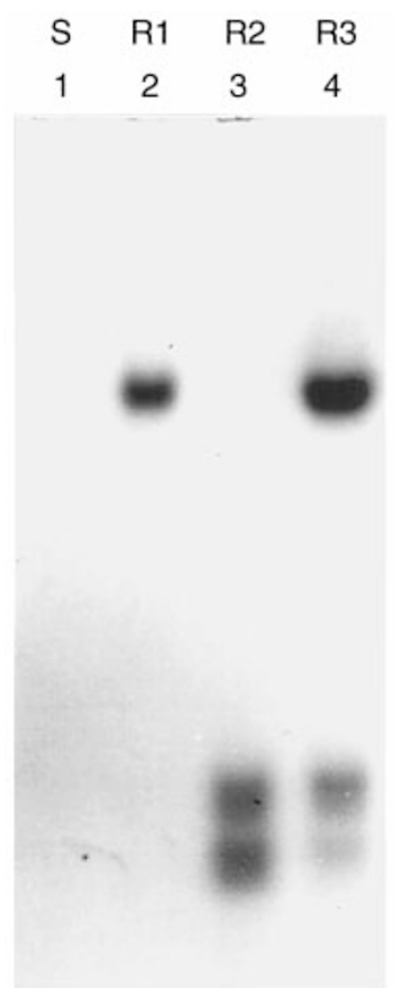

Fig. 1 Esterase patterns of greenbug clones. Lanes 1-4 represent susceptible $(\mathrm{S})$, pattern $1(\mathrm{R} 1)$, pattern 2 (R2) and pattern 3 (R3) Schizaphis graminum, respectively. Each lane contains the homogenate from a single aphid. Lanes 1-3 are representative of parental and offspring esterase phenotypes (S, R1 and R2), whereas lane 4 represents a novel offspring phenotype (R3) produced by an R1 male and an R2 female. bugs, the pattern of inheritance of the resistanceassociated esterases and the genetic basis for the presence of the elevated esterase activity have not been previously explored. In this study, the classical and molecular genetic techniques developed for this and other insect species were used to obtain information on the inheritance of insecticide resistance in the greenbug and to determine whether gene amplification and DNA methylation play a role in insecticide resistance in the greenbug.

\section{Materials and methods}

A single clone for each representative esterase phenotype (S, R1, R2) was chosen and used to study the inheritance of the elevated esterase phenotypes. The S clone originated in Atchison Co., KS (U.S.A.) in 1993. This clone has been determined to be biotype E. The R1 clone was collected in 1990 in Gray Co., KS (U.S.A.) and has been determined to be biotype I. The R2 clone was collected in Randall Co., TX (U.S.A.) in 1993, and is biotype E. These clones were previously identified by Rider \& Wilde (1998) as being capable of producing sexual morphs and viable offspring. The R2 clone has been demonstrated to produce only sexual females, whereas the other two clones (S, R1) produce both males and sexual females when exposed to the photoperiodic conditions and temperature regimes used in that study (Rider \& Wilde, 1998). For this study, induction of sexual morphs, egg collection, and rearing of offspring were as described by Rider \& Wilde (1998). Sexual morphs were tested to determine if males and oviparae expressed the elevated esterase phenotype and if the elevated esterases were sex-linked. Hatched offspring were collected and caged individually on wheat seedlings. All $F_{1}$ individuals that survived and reproduced parthenogenetically had their esterase phenotypes determined by polyacrylamide gel electrophoresis as described by Shufran et al. (1996). Data were analysed using a chi-squared goodness of fit test (Samuels, 1989) to determine if $F_{1}$ phenotypic ratios deviated from expected Mendelian segregation ratios. Subsequent clones of each $F_{1}$ were also examined for the presence of elevated esterase patterns to determine if phenotypic changes occurred during successive parthenogenetic cycles.

Southern blots were performed on several of the field-collected S, R1, and R2 clones described by Rider \& Wilde (1998), as well as on the parents and some of the $F_{1}$ offspring from the present inheritance study, to determine if restriction fragment length polymorphisms (RFLPs) or an intensified 
hybridization signal were associated with the esterase phenotypes when blots were probed with an esterase gene. A cloned $1.8 \mathrm{~kb}$ EcoRI/KpnI genomic fragment from Myzus persicae that contains a portion of the coding region for the E4 esterase gene was used as a heterologous probe (Field et al., 1993). Southern blots also were used to examine whether the esterase genes present in greenbugs were differentially methylated among various clones of the greenbug.

Total genomic DNA was isolated from greenbugs according to Jowett (1986) with the addition of an extra phenol/chloroform extraction, quantified spectrophotometrically, and adjusted to a final concentration of $100 \mu \mathrm{g} / \mathrm{mL}$. Four $\mu \mathrm{g}$ of genomic DNA from each of the clones examined were used for enzymatic digestions with EcoRI, HindIII, MspI and HpaII. Restriction-endonuclease digested DNAs were electrophoresed in $1 \%$ agarose gels in Trisacetate-EDTA buffer at $1.5 \mathrm{~V} / \mathrm{cm}$ for $16 \mathrm{~h}$ and transferred to nylon membranes by the method of Southern (1975).

Dot blots and densitometry were carried out to quantify the difference in signals obtained from $\mathrm{S}$ and R1 clones when identical amounts of genomic DNA were hybridized to the esterase gene probe. The DNAs from S and R1 aphids were denatured in a boiling-water bath for $10 \mathrm{~min}$ and then cooled quickly on ice. Concentrations ranging from 0.125 to $4.0 \mu \mathrm{g}$ of DNA were blotted to nylon membranes using a Hybrislot apparatus (Life Technologies, Gaithersburg, MD, U.S.A.). The DNAs were denatured on the membrane with a solution containing $0.5 \mathrm{M} \mathrm{NaCl}$ and $1 \mathrm{~m} \mathrm{NaOH}$, and neutralized in a solution containing $1.5 \mathrm{M} \mathrm{NaCl}$ and $0.5 \mathrm{M}$ Tris- $\mathrm{HCl}$, $\mathrm{pH}$ 7.2. The blots were rinsed with $2 \times \mathrm{SSC}$ and vacuum-dried at $80^{\circ} \mathrm{C}$ for $2 \mathrm{~h}$.

Prehybridization, hybridization, and washing of filters were performed at low stringency in aqueous solution according to Strauss (1994). The E4 probe was labelled by nick translation (Sambrook et al., 1989) with ${ }^{32}$ P-dCTP and used at a final concentration of $10-15 \mathrm{ng}$ probe $/ \mathrm{mL}$ of hybridization solution. Hybridization was carried out at $42^{\circ} \mathrm{C}$ for $16 \mathrm{~h}$. Following hybridization, filters were washed twice in $1 \times$ wash buffer $(0.3 \mathrm{M} \mathrm{NaCl}, 0.06 \mathrm{M}$ Tris- $\mathrm{HCl}$, $\mathrm{pH} 8.0,0.002 \mathrm{M}$ EDTA, pH 8.0), twice in $1 \times$ wash buffer containing $1 \%$ SDS, and twice in $0.1 \times$ wash buffer. Washes were performed for $30 \mathrm{~min}$ at $37^{\circ} \mathrm{C}$ with gentle shaking. Filters were air dried and exposed to X-ray film for $24 \mathrm{~h}$ at $-70^{\circ} \mathrm{C}$. Autoradiographs generated from Southern blots and dot blots were digitally imaged and analysed using IPLab Gel version 1.5 software (Signal Analytics, Vienna, VA, U.S.A.).

\section{Results and discussion}

Inheritance

The R2 greenbugs did not produce males, but produced oviparae under the conditions used for sexual morph production. Sib-matings and reciprocal crosses were not possible with this clone. The other clones produced both males and oviparae. Sexual morphs expressed the same esterase pattern as the clones from which they originated. No differences occurred among males or among oviparae of the same clone. However, males typically produced a much weaker signal than did oviparae. Sex determination in aphids is represented by an XX, XO system, where the chromosomal complement of males results from elimination of an $\mathrm{X}$ chromosome during the maturation division of parthenogenetic egg cells (Blackman, 1987). The gene or genes responsible for the R1 elevated esterase activity appear to reside on an autosome, because males did not show a 1:1 (R1:S) segregation ratio (of 10 examined, all were R1). Similar conclusions about the genes responsible for the R2 phenotype cannot be made because the $\mathrm{R} 2$ clone failed to produce males.

The results of the crosses are summarized in Table 1 . The $\mathrm{S}$ clone produced only susceptible offspring when inbred, indicating that the $\mathrm{S}$ clone did not carry any of the genes necessary for elevated esterase activity. Inbreeding and crossing the R1 clone to $\mathrm{R} 2$ and $\mathrm{S}$ clones produced $\mathrm{F}_{1}$ offspring whose phenotypic ratios were consistent with Mendelian segregation in which the gene or genes for R1 elevated esterase were inherited as a single unit. These ratios were consistent with the hypothesis that the R1 clone used in the crosses was heterozygous for the gene (or genes) conferring elevated esterase activity. The data were also consistent with the hypothesis that the R2 clone was heterozygous for the genes responsible for the R2 elevated esterase activity and that these genes were inherited as a single unit. No observable changes in esterase phenotype were detected in the offspring after 3-5 successive parthenogenetic cycles, suggesting that the esterase patterns were stable. The cross between the $\mathrm{R} 1$ clone and the $\mathrm{R} 2$ clone resulted in a single offspring whose esterase profile has not been shown to exist in nature. This individual contains both elevated esterase patterns (see Fig. 1). This clone has been designated pattern 3 (R3). The lack of R3 
Table 1 Inheritance of elevated esterase patterns in Schizaphis graminum

\begin{tabular}{llllll}
\hline $\begin{array}{l}\text { Cross } \\
(\mathrm{F} \times \mathrm{M})\end{array}$ & $n$ & \multicolumn{1}{c}{$\begin{array}{c}\text { Observed } \\
\text { ratios }\end{array}$} & \multicolumn{1}{c}{$\begin{array}{c}\text { Expected } \\
\text { ratios }\end{array}$} & \multicolumn{1}{c}{$\chi^{2}$} & Probability \\
\hline $\mathrm{S} \times \mathrm{S}$ & 53 & $53 \mathrm{~S}$ & $1 \mathrm{~S}$ & 0.00 & $>0.90$ \\
$\mathrm{~S} \times \mathrm{R} 1$ & 57 & $35 \mathrm{R} 1: 22 \mathrm{~S}$ & $1 \mathrm{R} 1: 1 \mathrm{~S}$ & 2.96 & $0.10-0.05$ \\
$\mathrm{R} 1 \times \mathrm{S}$ & 55 & $26 \mathrm{R} 1: 29 \mathrm{~S}$ & $1 \mathrm{R} 1: 1 \mathrm{~S}$ & 0.16 & $0.75-0.50$ \\
$\mathrm{R} 1 \times \mathrm{R} 1$ & 56 & $42 \mathrm{R} 1: 14 \mathrm{~S}$ & $3 \mathrm{R} 1: 1 \mathrm{~S}$ & 0.00 & $>0.90$ \\
$\mathrm{R} 2 \times \mathrm{S}$ & 29 & $10 \mathrm{R} 2: 19 \mathrm{~S}$ & $1 \mathrm{R} 2: 1 \mathrm{~S}$ & 2.97 & $0.75-0.50$ \\
$\mathrm{R} 2 \times \mathrm{R} 1$ & $13^{*}$ & 6 R1:3 R2:3 S:1 R3 & 1 R1:1 R2:1 S:1R3 & 3.92 & $0.050-0.025$ \\
\hline
\end{tabular}

S, susceptible; R1, pattern 1; R2, pattern 2; R3, both pattern 1 and pattern 2 . *The sample size is too small for the chi-squared analysis to be accurate (Samuels, 1989).

individuals in nature is best explained by the low percentage of resistant clones (both R1 and R2) that are present in nature (Wilde et al., 1994), combined with the observations that the few resistant clones capable of sexual reproduction are significantly less fecund than insecticide-susceptible clones (Rider \& Wilde, 1998). For unknown reasons, the R3 clone failed to produce sexual morphs but continued to produce parthenogenetic females when exposed to the long scotophase required for sexual morph production. This eliminated the ability to perform informative test-crosses. Previous investigations with greenbugs have shown that clones which have not undergone several generations of apomictic reproduction under a long photoperiod will not enter the sexual cycle (Ullah \& Peters, 1996). It is possible that the R3 clone may be capable of future sexual reproduction if exposed to the appropriate environmental stimuli.

\section{Dot blots and Southern blots}

The DNA digested with EcoRI produced identical bands in all insects (Fig. 2), but one of the EcoRI bands was more intense in R1 and R3 insects. The DNA digested with HindIII (Fig. 2) produced different patterns between insects bearing the R1 esterase (R1 and R3) and those not bearing the R1 esterase (S and R2). Based on densitometry, DNA from R1 insects produced a hybridization signal approximately twofold greater than DNA from S clones when identical amounts of DNA were compared (Fig. 3). The results presented in Figs 2 and 3 were identical to those obtained with the DNA from several independent field-derived clones (data not presented).

The intensified signal and unique restriction sites associated with the R1 esterase suggests that the mechanism for the R1 elevated esterase activity is gene amplification. It is difficult to elaborate upon the exact degree of gene amplification present in R1 individuals. The gene probe used encompasses DNA sequences shown to be conserved among several different serine esterases from a number of different insect species (Field et al., 1993). It is possible that this probe hybridized to several different esterase genes in the greenbug because the hybridization and washing conditions used were of very low stringency. Conclusions about the mechanism behind the R2

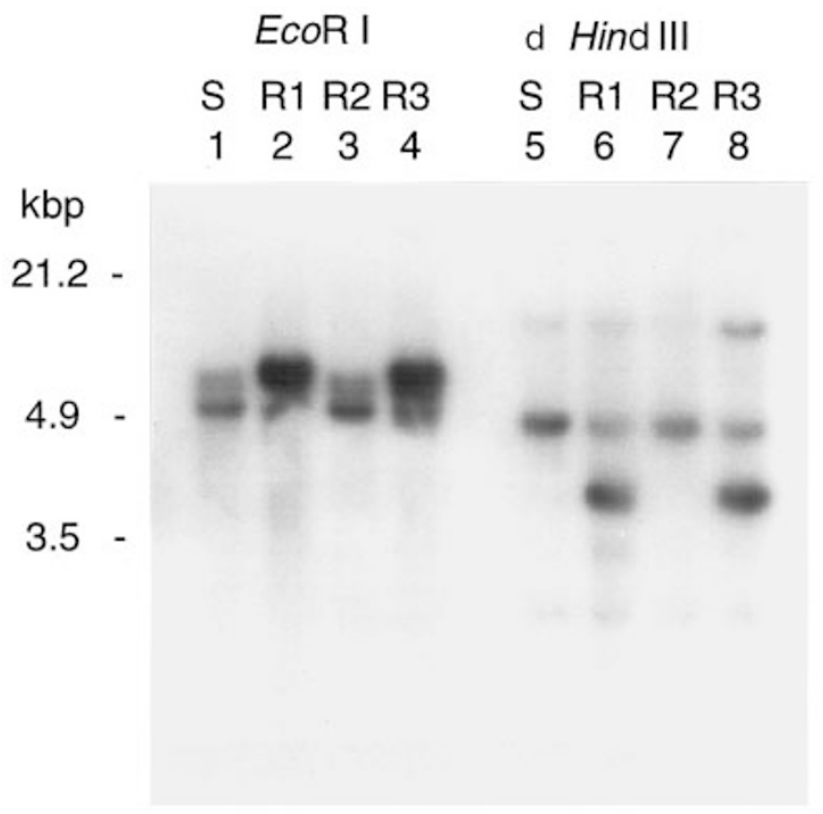

Fig. 2 Southern blot of Schizaphis graminum genomic DNA. Lanes 1-4: EcoRI-digested DNA of susceptible (S), pattern 1 (R1), pattern 2 (R2) and pattern 3 (R3) aphids. Lanes 5-8: HindIII-digested DNA of S, R1, R2 and R3 aphids. Each lane contains $4 \mu \mathrm{g}$ of DNA. Left side of figure displays molecular weights in kilobase pairs (kbp). 


\section{$\begin{array}{llllll}1 & 2 & 3 & 4 & 5 & 6\end{array}$}

S

R1

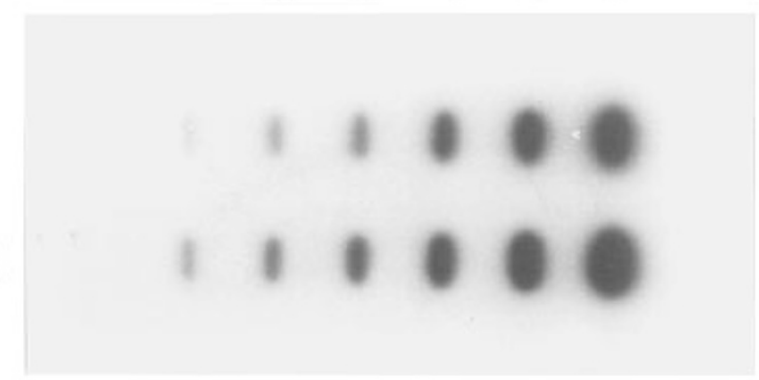

\section{$\begin{array}{lllllll}0.125 & 0.25 & 0.5 & 1.0 & 2.0 & 4.0 \mu \mathrm{g}\end{array}$}

Fig. 3 Dot blot of susceptible (S) and pattern 1 (R1) DNA of Schizaphis graminum. Slots 1-6 contain 0.125, $0.25,1.0,2.0$ and $4.0 \mu \mathrm{g}$ of DNA, respectively. Note the intensity of signal from R1 insects (compare signal from $0.125 \mu \mathrm{g}$ R1 DNA to that of $0.25 \mu \mathrm{g}$ of S DNA).

elevated esterase activity cannot be drawn because no differential hybridization (either intensified signal, or RFLP) was observed between R2 and S insects. However, the observation that R2 insects do not display hybridization patterns similar to R1 insects suggests a different genetic mechanism (altered transcriptional or translational control, amplification in a different gene, or a gene coding an enzyme with increased catalytic activity) may be involved in the elevated esterase activity found in R2 insects. This finding contrasts strongly with those in Myzus persicae where different elevated esterase patterns result from the amplification of nearly identical genes (Field et al., 1988, 1993).

We have found differential methylation patterns for the esterase-related gene sequences present in greenbug DNA (Fig. 4). This information is limited, and the relationship between DNA methylation and insecticide resistance in the greenbug is unclear at the present time.

\section{Concluding remarks}

This study provides an initial contribution towards understanding the genetic mechanisms behind insecticide resistance in the greenbug. The pattern of inheritance of the elevated esterase activity for the R1 esterase combined with the stronger hybridization signal and RFLP for esterase-related gene sequences in R1 insects suggests that a single locus containing an amplified esterase gene is responsible for the increased esterase activity in the R1 clone used in the inheritance study. This information, along with the identical restriction patterns among different R1 clones reported here suggests a conserved mechanism like that found in the aphid species $M$. persicae and $M$. nicotianae (Field \& Devonshire, 1992). The relationships between the genes responsible for the two elevated esterase patterns (R1 and R2) and the significance of differential DNA methylation in esterase-related DNA

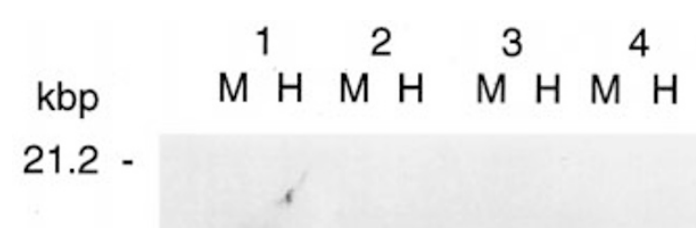

$4.9-$

3.5

$1.9-$

$0.9-$

$0.5-$

$0.1-$

Fig. 4 Southern blot to identify differential methylation in esterase genes among clones of Schizaphis graminum. Each pair of lanes contains the DNA from a different aphid clone digested with MspI (M) or HpaII (H). Absence of a higher molecular weight band (with a concomitant increase in signal for a lower molecular weight band) in an MspI digest compared to an HpaII digest indicates methylation at the internal cytosine in the DNA sequence 5'-CCGG-3' located in or near esteraserelated gene sequences. Presence of high molecular weight bands in both digests indicates that the $5^{\prime}$ cytosine is methylated in the sequence described above. Left side of figure displays molecular weights in kilobase pairs (kbp).

(C) The Genetical Society of Great Britain, Heredity, 81, 14-19. 
sequences in the greenbug are unclear at the present time. More work towards understanding the genetic basis of insecticide resistance in the greenbug will strengthen our understanding of the development of insecticide resistance in this and other economically important species.

\section{Acknow ledgements}

The authors thank Linda M. Field, Rothamsted Experimental Station, Harpenden, Hertfordshire, UK, for providing a clone of the E4 gene. It was an important and integral part of this research. We also thank the Electron Microscope Facility in Agriculture, Purdue University, West Lafayette, IN for the use of their densitometric analysis hardware and software. This is contribution number 97-399-J of the Kansas Agricultural Experiment Station.

\section{References}

BLACKMAN, R. L. 1987. Reproduction, cytogenetics and development. In: Minks, A. K. and Harrewijn, P. (eds) World Crop Pests: Aphids, their Biology, Natural Enemies and Control, vol. 2A, pp. 163-195. Elsevier Science Publishing Company, New York.

BLACKMAN, R. L., SPENCE, J. M., FIELD, L. M., JAVED, N., DEVINE, G. J. AND DEVONSHIRE, A. L. 1996. Inheritance of the amplified esterase genes responsible for insecticide resistance in Myzus persicae (Homoptera: Aphididae). Heredity, 77, 154-167.

FERrARI, J. A. AND GEORGHIOU, G. P. 1991. Quantitative genetic variation of esterase activity associated with a gene amplification in Culex quinquefasciatus. Heredity, 66, 265-272.

FIELD, L. M. AND DEVONSHIRE, A. L. 1992. Esterase genes conferring insecticide resistance in aphids. In: Mullin, C. A. and Scott, J. G. (eds) Molecular Mechanisms of Insecticide Resistance Diversity Among Insects, pp. 209-217. American Chemical Society, Washington, DC.

FIELD, L. M., DEVONShIRE, A. L. AND FORDE, B. G. 1988. Molecular evidence that insecticide resistance in peach-potato aphids (Myzus persicae Sulz.) results from amplification of an esterase gene. Biochem. J., 251, 309-312.

FIELD, L. M., WILLIAMSON, M. S., MOORES, G. D. AND DEVONSHIRE, A. L. 1993. Cloning and analysis of the esterase genes conferring insecticide resistance in the peach- potato aphid Myzus persicae (Sulzer). Biochem. J., 294, 569-574.

JOWETt, т. 1986. Preparation of nucleic acids. In: Roberts, D. B. (ed.) Drosophila: A Practical Approach, pp. 275-286. IRL Press, Oxford.

MOUCHES, M., PASTEUR, N., BERGE, J. B., HYRIEN, O., RAYMOND, M., DE SAINT VINCENT, B. R. ETAL. 1986. Amplification of an esterase gene is responsible for insecticide resistance in a California Culex mosquito. Science, 233, 778-780.

ONO, M., RICHMAN, J. S. AND SEIGFRIED, B. D. 1994. In vitro metabolism of parathion in susceptible and parathionresistant strains of the greenbug, Schizaphis graminum (Rondani) (Homoptera: Aphididae). Pestic. Biochem. Physiol., 45, 24-33.

RIDER, S. D., JR. AND WILDE, G. E. 1998. Variation in fecundity and sexual morph production among insecticide resistant clones of the aphid Schizaphis graminum (Homoptera: Aphididae). J. Econ. Entomol. (in press).

RIDER, S. D., JR., DOBESH, S. M. AND WILDE, G. E. 1998. Insecticide resistance in a novel laboratory-produced greenbug (Homoptera: Aphididae) clone. J. Econ. Entomol., 91, 30-33.

SAMBROOK, J., FRITSCH, E. F. AND MANiATIS, T. 1989. Molecular Cloning: A Laboratory Manual, 2nd edn. Cold Spring Harbor Laboratory Press, Cold Spring Harbor, NY.

SAMUels, M. L. 1989. Statistics for the Life Sciences. Dellen Publishing Company, San Francisco, CA.

SHUfRAN, R. A., WILDE, G. E. AND SLODERBECK, P. E. 1996. Description of three isozyme polymorphisms associated with insecticide resistance in greenbug (Homoptera: Aphididae) populations. J. Econ. Entomol., 89, 46-50.

SIEGFRIED, B. D. AND ONO, M. 1993. Mechanisms of parathion resistance in the greenbug Schizaphis graminum (Rondani). Pestic. Biochem. Physiol., 45, 24-33.

SOUTHERN, E. M. 1975. Detection of specific sequences among DNA fragments separated by gel electrophoresis. J. Mol. Biol., 98, 503-517.

STRAuSS, w. M. 1994. Hybridization with radioactive probes. In: Ausubel, F. M., Brent, R., Kingston, R. E., Moore, D. D., Seidman, J. G., Smith, J. A. and Struhl, K. (eds) Current Protocols in Molecular Biology, pp. 6.3.1-6.3.6. John Wiley and Sons, New York.

Ullah, F. AND PETERS, D. C. 1996. Sexual reproduction capabilities of greenbugs (Homoptera: Aphididae). $J$. Kans. Entomol. Soc., 69, 153-159.

WILDE, G., SHUFRAN, R. AND BOWLING, R. 1994. Insecticide resistance among biotype I greenbugs (Homoptera: Aphididae). J. Kans. Entomol. Soc., 66, 453-454. 